\title{
The thrombospondin-1 receptor CD36 is an important mediator of ovarian angiogenesis and folliculogenesis
}

\author{
Kata Osz, Michelle Ross and Jim Petrik
}

\begin{abstract}
Background: Ovarian angiogenesis is a complex process that is regulated by a balance between pro- and anti-angiogenic factors. Physiological processes within the ovary, such as folliculogenesis, ovulation, and luteal formation are dependent upon adequate vascularization and anything that disrupts normal angiogenic processes may result in ovarian dysfunction, and possibly infertility. The objective of this study was to evaluate the role of the thrombospondin-1 (TSP-1) receptor CD36 in mediating ovarian angiogenesis and regulating ovarian function.

Methods: The role of CD36 was evaluated in granulosa cells in vitro and ovarian morphology and protein expression were determined in wild type and CD36 null mice.

Results: In vitro, CD36 inhibition increased granulosa cell proliferation and decreased apoptosis. Granulosa cells in which CD36 was knocked down also exhibited an increase in expression of survival and angiogenic proteins. Ovaries from CD36 null mice were hypervascularized, with increased expression of pro-angiogenic vascular endothelial growth factor (VEGF) and its receptor VEGFR-2. Ovaries from CD36 null mice contained an increase in the numbers of pre-ovulatory follicles and decreased numbers of corpora lutea. CD36 null mice also had fewer number of offspring compared to wild type controls.
\end{abstract}

Conclusions: The results from this study demonstrate that CD36 is integral to the regulation of ovarian angiogenesis by TSP-1 and the expression of these family members may be useful in the control of ovarian vascular disorders.

Keywords: Ovary, CD36, Thrombospondin, Folliculogenesis, Angiogenesis

\section{Background}

Ovarian folliculogenesis, ovulation, and formation of the corpus luteum require complex and coordinated interaction of numerous autocrine, paracrine, and endocrine factors to regulate important physiologic processes such as angiogenesis. Angiogenesis is the formation of new blood vessels from pre-existing vasculature. In the adult, angiogenesis is generally quiescent except for the vascularization required for wound healing. However, the female reproductive tract, including the ovaries, and uterus are unique as they are adult tissues that undergo cyclic angiogenic processes to facilitate processes important to reproduction. An important regulator of ovarian angiogenesis is vascular

\footnotetext{
*Correspondence: jpetrik@uoguelph.ca

Department of Biomedical Sciences, University of Guelph, Guelph, ON N1G 2W1, Canada
}

\section{Biomed Central}

endothelial growth factor (VEGF), which stimulates endothelial proliferation, migration, and survival, and we have shown that through interaction with its receptor VEGFR2, it is an important survival factor for extravascular ovarian cells [1].

Thrombospondin-1 (TSP-1) is a large $(450 \mathrm{kDa})$ multimodular glycoprotein encoded by the THSB1 gene that was originally identified as a major component of platelet $\alpha$-granules [2,3]. Since then, TSP-1 has been shown to be an important matricellular protein that mediates cell signaling, wound healing, cell adhesion, and angiogenesis $[4,5]$. Of TSP-1's many biological functions, likely the most notable effect is the inhibition of angiogenesis [6]. The effects of TSP-1 in tumorigenesis have been well-studied. Reduced expression of TSP-1 is usually associated with aggressive angiogenesis and enhanced tumour formation [7], 
while TSP-1 over-expression generally results in inhibited tumour formation and reduced tumour vessel density [8]. During tumour development, TSP-1 is typically inversely associated with pro-angiogenic markers such as vascular endothelial growth factor (VEGF) where tumours with a higher TSP-1:VEGF ratio are typically slower growing, while tumours that favor VEGF expression are aggressive and have a higher rate of malignancy $[9,10]$.

CD36 is a multi-ligand glycoprotein receptor, although it is best known for binding TSP-1. CD36 is known to act as a transporter and sensor of free fatty acids [11,12] and a scavenger receptor that binds a number of factors and participates in the internalization of cells, pathogens, and various lipoproteins [13]. CD36 is an $88-\mathrm{kDa}$ integral plasma membrane protein and is expressed by a variety of cells including platelets, erythrocytes, endothelial cells, monocytes, granulosa, theca, and tumour cells [14-16]. Likely one of the most well-established functions of CD36 is the inhibition of angiogenesis following binding to the Type I repeats (TSR) of TSP- 1 and -2 $[17,18]$. Following binding of TSR, CD36 initiates antiangiogenic signals through the induction of endothelial cell apoptosis $[19,20]$. TSP-1 stimulates CD36 to recruit non-receptor protein kinases fyn, lyn and yes to the CD36 complex [21]. This recruitment results in the activation of the kinase and initiation of the p38 mitogen activated protein kinase (MAPK) pathway, initiation of caspase-3-like effectors, and ultimately apoptotic cell death [14].

TSP-1 and CD36 are coordinately expressed in granulosa and theca cells of rodent [16] and bovine [15] ovaries. Expression of the ligand and receptor vary throughout the reproductive cycle and are regulated at least in part by gonadotropins [16]. Cyclical expression of TSP-1 is associated with changes in ovarian angiogenesis, where reduced expression of the protein accompanies increased perafollicular and luteal angiogenesis during period of follicular and luteal development [16].

We have shown that TSP-1 Null mice are subfertile and have altered ovarian morphology highlighted by increased vascularization and disrupted follicle dynamics, compared with wild-type controls [22]. TSP-1 and its mimetic peptides have been shown to reduce VEGF expression, inhibit ovarian angiogenesis, and induce follicle atresia $[23,24]$. These findings led us to believe that TSP-1 and pro-angiogenic VEGF had reciprocal inhibitory influences in the ovary and we demonstrated that TSP-1 bound VEGF, resulting in its internalization and degradation through the low density lipoprotein receptor related protein (LRP)-1. However, the extent of the ovarian morphological and functional alterations in the TSP1 null mice could not be accounted for exclusively by a direct interaction between TSP-1 and VEGF. We anticipated that in addition to VEGF-mediated effects, CD36 signaling may have specific influences on ovarian function.
In ovarian tumor development, we demonstrated that treatment with TSP-1 mimetic peptides inhibited tumor formation, and that this effect was abrogated when CD36 expression was knocked down [25]. Based on the coordinated expression of TSP-1 and CD36 during ovarian follicle development, and the results from our work in the ovarian cancer model, we hypothesized that CD36 is an important mediator in the regulation of ovarian cell function and folliculogenesis.

\section{Methods}

\section{Cell lines and tissue collection}

Spontaneously immortalized rat granulosa cells (SIGC) were generously provided by Dr. Robert Burghardt (Texas A\&M University, College Station, TX) and were cultured in DMEM/F12 (Gibco BRL), supplemented with 10\% FBS, and 1\% Antibiotic/Antimycotic (Gibco BRL). The SIGCs are derived from primary rat ovarian granulosa cell cultures and grow in culture without undergoing luteinization [26]. We have previously shown that these cells express the CD36 receptor [16]. CD36-null mice and wild type (WT) C57BL-6 littermates were a generous gift from Dr. Arend Bonen, Department of Health and Human Nutrition, University of Guelph, Guelph, ON. All animal work was carried out in compliance with guidelines established by the Canadian Council on Animal Care. For in vivo tissue collection, approximately 30 -week old littermate WT and $\mathrm{CD}^{-1-}$ mice $(\mathrm{n}=8 /$ group) were injected intraperitoneally with 2.5 IU PMSG (Sigma) to initiate a synchronous follicular wave. $48 \mathrm{hr}$ after injection, mice were euthanized via $\mathrm{CO}_{2}$ asphyxiation and ovaries were collected at the late antral/preovulatory phase of the cycle and either flash frozen for protein collection, or fixed overnight in 10\% neutral buffered formalin.

\section{CD36 knockdown in SIGC}

miRNA construct: The following complementary single stranded oligonucleotides were synthesized by SigmaAldrich: Rmi615640_top_cd36 - TGCTGTTCCTTGG CTAAATAACGAACGTTTTGGCCACTGACTGACGT TCGTTATAGCCAAGGAA.

Rmi615640_bot_Cd36 - CCTGTTCCTTGGCTATAA CGAACGTCAGTCAGTGGCCAAAACGTTCGTTATT TAGCAAGGAAC.

Oligonucleotide strands were annealed and ligated into pcDNA 6.2-GW/EmGFP-miR vector (Life Technologies) then transformed into TOP10 cells (Life Technologies) according to the manufacturer's instructions. In addition to the CD36 knockdown oligonucleotides, scrambled sequence oligos with similar G/C content (Life Technologies) were also used as recommended.

Plasmids were purified by the Qiagen plasmid purification mini kit. Plasmids were sequenced (Laboratory Services, University of Guelph) to confirm the sequence 
A
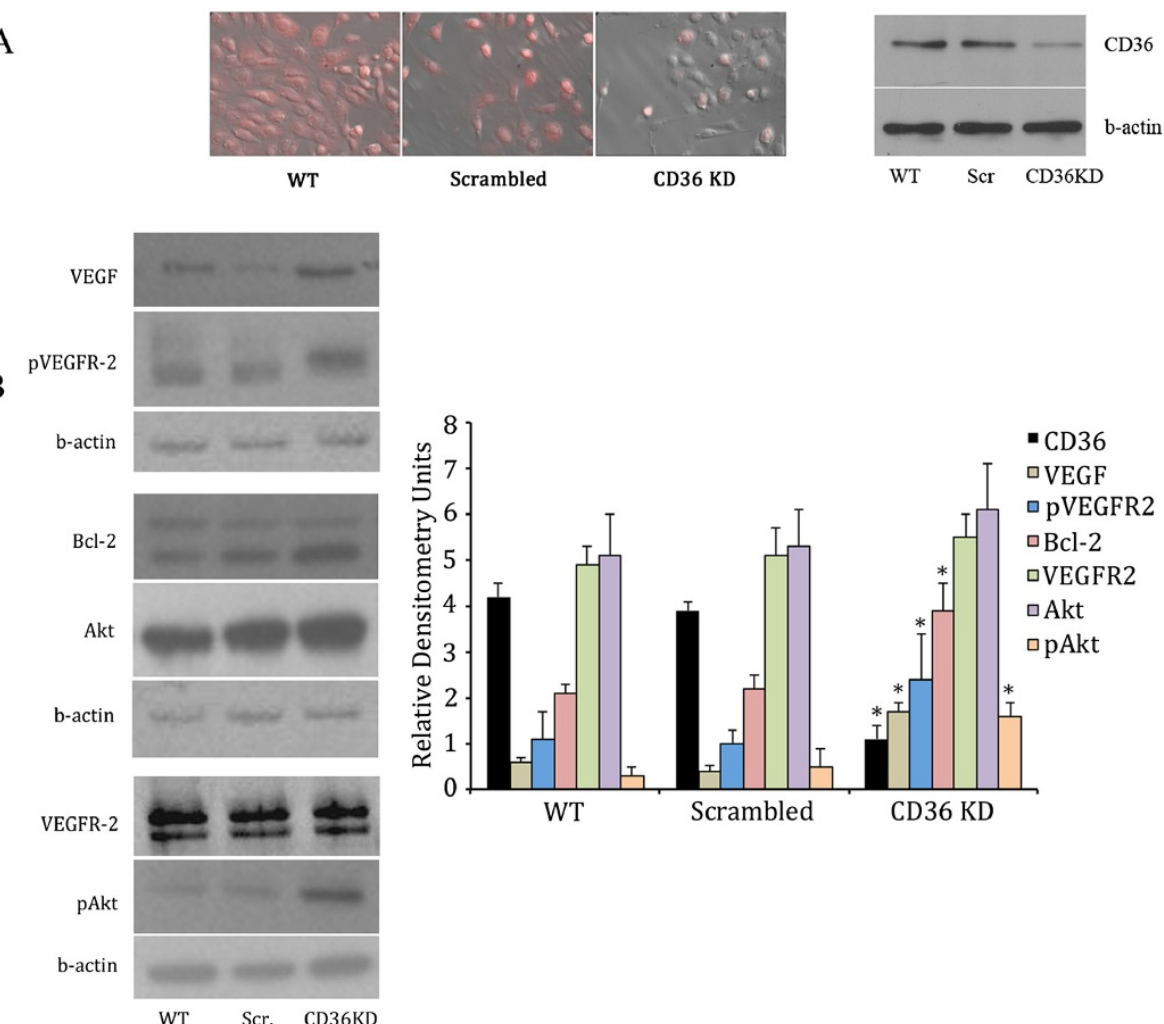

\section{C}

SF
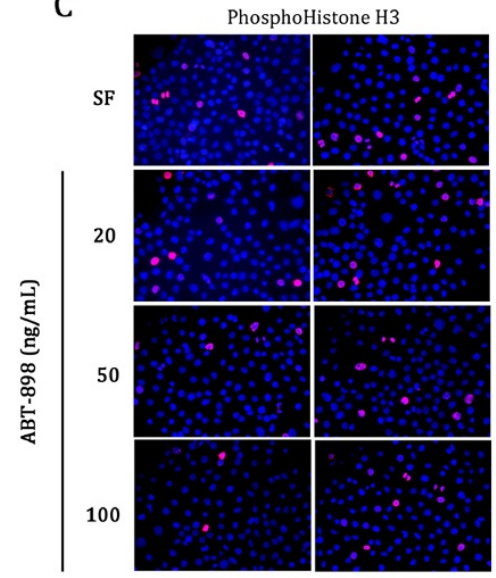

WT

CD36 KD

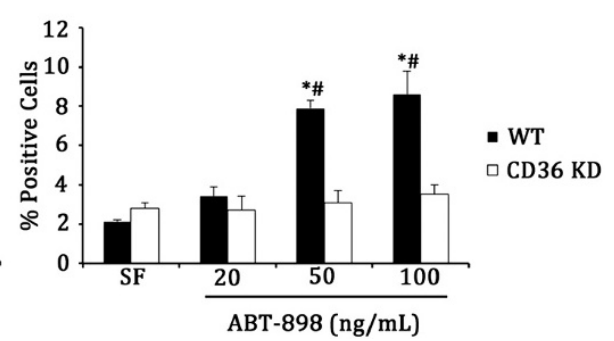

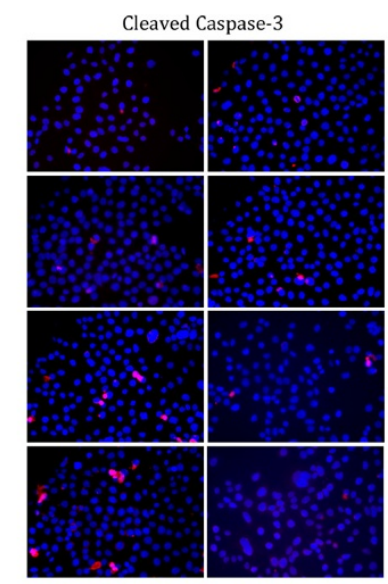

WT

CD36 KD

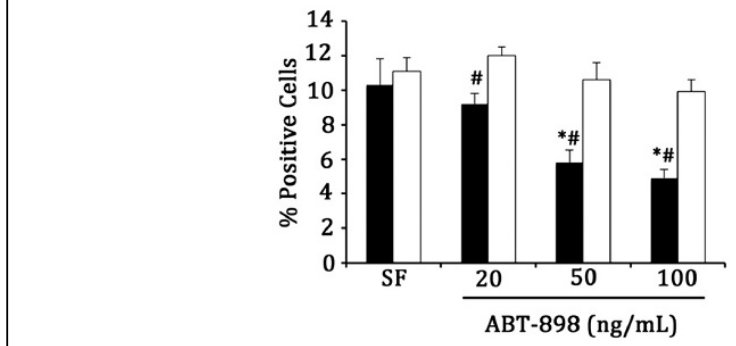

Figure 1 (See legend on next page.) 


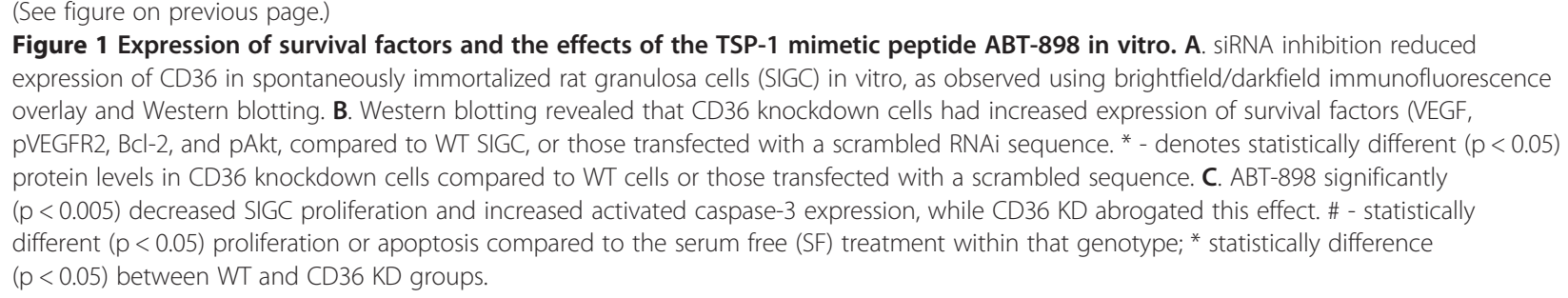

identity of the oligo. $1 \times 10^{5} / \mathrm{ml}$ SIGC cells were cultured in DMEM $\backslash F 12$ (Gibco) supplemented with 10\% FBS without antibiotic on 24 well plates. At approximately $70 \%$ confluence medium was removed, cells were washed in PBS, and $500 \mathrm{ul} /$ well 1xOPTI-MEM reduced serum medium (Gibco) was added. Transfection was achieved using Lipofectamine2000 (Invitrogen) according to the manufacturer instructions. Stable cell lines were established from single-cell dilution colonies, plated in $10 \mathrm{ug} /$ $\mathrm{ml}$ blasticidin (Invitrogen) for approximately 2 weeks to ensure elimination of any non-transfected cells. Stable cell line generation was confirmed with confocal microscopy to localize plasmid GFP within the SIGCs. To confirm knockdown, brightfield/darkfield immunofluorescence overlays with a phase-contrast inverted fluorescence microscope and Western blot analysis were performed on WT, Scrambled, and CD36KD SIGC in the log growth phase (Figure 1).

\section{Hormone assays, ovarian morphometry, and fertility}

At the late antral/ovulatory phase of the ovarian cycle, WT and CD36- - - mice were killed by $\mathrm{CO}_{2}$ asphyxiation and blood was collected in a heparinized syringe via cardiac puncture and centrifuged at $1,000 \times \mathrm{g}$ for $10 \mathrm{~min}$ at $4^{\circ} \mathrm{C}$. The plasma supernatant samples were collected and stored at $-80^{\circ} \mathrm{C}$ until assayed. $\mathrm{LH}$ was assessed by using an ELISA kit from Endocrine Technologies (Newark, CA) (sensitivity, $0.5 \mathrm{ng} / \mathrm{ml}$; intra-assay variation, $7 \%$; inter-assay variation, 9.8\%). FSH was measured by using an ELISA kit from Biocode-Hycel (sensitivity, $0.2 \mathrm{ng} / \mathrm{ml}$; intra-assay variation, $4.7 \%$; inter-assay variation, $8.5 \%$ ). Ovaries were also collected, fixed in $10 \%$ neutral buffered formalin, processed, embedded in paraffin and $5 \mu \mathrm{m}$ thick sections were cut throughout the entire tissue with a rotary microtome. For ovarian morphology assessment, every $5^{\text {th }}$ slide was subjected to Hematoxylin/Eosin staining and was used for counting of follicles and corpora lutea. Pre-antral/antral follicles and corpora lutea were counted in the 2 groups of mice ( $n=6$ /group). As an index of fertility, ovarian synchronization was performed in a separate cohort of WT and CD36-/- null littermate mice ( $\mathrm{n}=6$ /group). Mice were injected with 2.5 IU PMSG, followed $48 \mathrm{hr}$ later with $5 \mathrm{IU}$ hCG (Sigma) to induce ovulation. Mice were immediately paired with proven male breeder mice and left together for one week before the male was removed. Mice were monitored for approximately 20 days following mating and the number of offspring from the female mice was counted.

\section{Cell proliferation and apoptosis}

To identify the role of CD36 in TSP-1 mediated granulosa cell proliferation and apoptosis, SIGC were subjected to RNAi knockdown as described above. WT and CD36 knockdown (CD36 KD) cells were plated in 24 well plate on glass coverslips. At $60 \%$ confluence, medium was changed to reduced serum (1\% FBS) DMEM/F12 medium (Gibco) overnight. Cultures were treated with 0 , 20,50 or $100 \mathrm{ng} / \mathrm{ml}$ of the TSP-1 mimetic peptide ABT898 for 24 hours. Following treatment, cells were rinsed in PBS and fixed for 1 hour in 10\% (vol/vol) neutral buffered formalin. Cells were then permeabililzed with $1 \%$ Triton X-100 (Sigma) in PBS for 15 min, followed by blocking in $5 \%$ BSA $/ 0.1 \%$ Sodium Azide in PBS for 10 min. Cells were then either incubated overnight at $4{ }^{\circ} \mathrm{C}$ with antibodies to phosphorylated Histone $\mathrm{H} 3$ antibody (proliferation; 1:2000 dilution; Abcam, ab5176) or anti-active Caspase3 antibody (apoptosis; 1:500 dilution; Millipore, ab3623) followed by Alexa-Fluore 594-labeled donkey anti-rabbit secondary antibody (1:500 dilution, Invitrogen) for $1 \mathrm{hr}$ at room temperature. After rinsing, cells were stained with $2 \mathrm{ug} / \mathrm{ml}$ DAPI (Sigma) to counterstain nuclei blue and mounted on glass slides (SuperFrost Plus, Fisher) with Prolong Gold antifade solution (Invitrogen). Epifluorescence microscopy was used for image acquisition and integrated morphometry software (Metamorph, Burlingname, CA) was used to quantify the percent immunopositive cells in follicles without (pre-antral) or with (antral) an antrum, and in corpora lutea.

\section{Immunohistochemistry}

Five micrometer-thick paraffin embedded ovarian tissue sections from wild-type and $\mathrm{CD}_{3} 6^{-1-}$ mice were incubated overnight at $4^{\circ} \mathrm{C}$ in a humidified chamber with rabbit polyclonal anti-VEGF antibody (1:600 dilution; Santa Cruz Biotechnology, CA, sc152), rabbit polyclonal anti-VEGFR-2 antibody (1:200 dilution; Cell Signaling, 2479); goat polyclonal anti-TSP-1 antibody (1:600 dilution; Santa Cruz, sc59887); mouse monoclonal anti-CD31 (1:500 
dilution; Abcam; ab28634); or mouse monoclonal antiKi67 antibody (1:500 dilution; Sigma, Oakville, ON, SAB4501880). The following day, biotinylated secondary antibody (1:100 dilution, Sigma) was applied for $2 \mathrm{hr}$ at room temperature (RT), followed by horseradish peroxidase (Extravidin, 1:50 dilution, Sigma) for $1 \mathrm{hr}$ at RT. Antigen localization was provided with incubation in DAB solution (SigmaFast 3,3'-Diaminobenzidine tablets), and tissues were counterstained with Carazzi's Hematoxylin, dehydrated, cleared in xylene and mounted on coverslips. Images were captured using brightfield microscopy and the percentage of immunopositive tissue was quantified using a computer-generated thresholding algorithm and analysis (Aperio, ImageScope) for VEGF, VEGFR-2, and TSP-1 immunostaining. For CD31 staining, blood vessel density was calculated as the percentage of ovarian tissue comprised of CD31-postive endothelium using integrated morphometry software (Metamorph, CA). Ki67 staining in follicular and luteal cells were quantified manually by two independent observers blinded to whether the slides belonged to WT or $\mathrm{CD} 36^{-1-}$ mice.

\section{Western blot analysis}

Total cellular proteins were isolated from wild type and transfected SIGC cells and ovarian tissue from WT and $\mathrm{CD}^{-1-}$ mice using standard RIPA buffer containing protease inhibitor cocktail. Denatured 20ug and 40ug protein were loaded to $4-15 \%$ gradient PAGE gel (Mini protean TGX Gel, BioRad) and transferred to polyvinylidene fluoride (PVDF) membrane (Millipore), blocked (5\% skim milk in TBST) for 1 hour at room temperature. For in vitro experiments, primary antibodies with disparate molecular weights were incubated on the pvdf membrane that was cut around the area of the predicted molecular weight. Membranes were incubated with VEGF (1:500, Santa Cruz), TSP-1 (1:200, santa cruz), Bcl-2 (1:500, Novus Biological), VEGFR2 (1:2000, Cell Signaling), phospho VEGFR-2 (1: 500, Cell Signaling), CD36 (1:400, BD Pharmingen), Akt (1:100, Cell Signaling), phosphoAkt (1:500, Cell Signaling) and B-actin (1:4000, Cell Signaling) overnight at $4 \mathrm{C}$ on a rocking platform. Blots were washed in TBS with 1\% Tween 20 (TBST) and incubated in appropriate dilutions of secondary antibodies (anti-rabbit IgGHRP; anti-mouse IgG-HRP, Cell Signaling). Reactive protein was detected with Western Lightning Chemiluminescence Reagent Plus (PerkinElmer) on X-ray film (Kodak ClinicSelect blue). For some blots in which one of the primary antibodies was similar size to $\beta$-actin, the membrane was stripped using Millipore Re-Blot Plus MildTM (Millipore) for $15 \mathrm{~min}$ at RT, followed by 2 washes of 5\% skim milk in TBST before re-probing with $\beta$-actin primary antibody and anti-rabbit secondary antibody. Films were imaged and densitometry analysis was performed using an AlphaInnotech imaging station.

\section{Statistical analysis}

Three replicates of all data were performed and used to determine statistical significance. For immunohistochemistry experiments, a minimum of 5 fields of view at 200× magnification were used. Statistical analysis was performed using a one-way ANOVA, followed by Bonferonni's post-hoc test. $\mathrm{P}$ values are listed in the figure legends.

\section{Results}

Knockdown of CD36 causes increased granulosa cell proliferation and survival

To evaluate the role of CD36 in granulosa cell function, we inhibited expression of the receptor in granulosa cells using RNA interference. With the RNA interference, we were able to reduce SIGC expression of CD36 by approximately $75 \%$ compared to WT cells or those transfected with scrambled oligonucleotide sequence (Figure 1A/B). Following knockdown, SIGCs had increased expression of the pro-angiogenic proteins VEGF and phosphorylated VEGFR2 (Figure 1B). SIGCs also exhibited an increase in protein levels of the cytoprotective proto-oncogene $\mathrm{Bcl}-2$ and the pro-proliferative and pro-survival phosphorylated Akt (Figure 1B). In in vitro experiments the Thrombospondin-1 mimetic peptide ABT-898 caused a significant $(\mathrm{p}<0.05)$ decrease in SIGC proliferation in WT cells, but there was no change in proliferation in SIGCs that had CD36 knocked down (Figure 1C). Conversely, ABT-898 induced SIGC apoptosis in WT cells, but this effect was abrogated with CD36 knockdown (Figure 1C).

\section{Ovarian morphometry, gonadotropin production and number of offspring are altered in CD36-I- mice}

Serum samples from WT and CD36 ${ }^{-1-}$ mice were collected at the time of euthanasia and subjected to ELISA analysis for leutenizing hormone (LH) and follicle stimulating hormone $(\mathrm{FSH})$. FSH levels were significantly $(\mathrm{p}<0.05)$ higher in CD36 null mice compared to WT controls (Figure 2A), while LH levels in circulation were significantly $(\mathrm{p}<0.05)$ reduced compared to controls (Figure 2A). When ovarian structures were tabulated, there was a significant $(\mathrm{p}<0.01)$ increase in the number of total follicles (including pre-antral, antral, and pre-ovulatory follicles) in CD36-I- mice compared to WT controls (Figure 2B). Conversely, CD36 ${ }^{-1-}$ mouse ovaries contained significantly $(\mathrm{p}<0.05)$ fewer corpora lutea than WT mouse ovaries (Figure $2 \mathrm{~B}$ ). The number of live offspring born from $\mathrm{CD} 36^{-1-}$ mice was significantly $(\mathrm{p}<0.05)$ lower than those from WT mothers (Figure $2 \mathrm{C}$ ).

\section{Ovaries from $\mathrm{CD}^{-1-}$ mice have higher expression of pro-angiogenic and pro-survival factors, compared to ovaries from WT controls}

Mice from both groups had their ovarian cycles synchronized and ovaries were collected at the late antral/pre- 


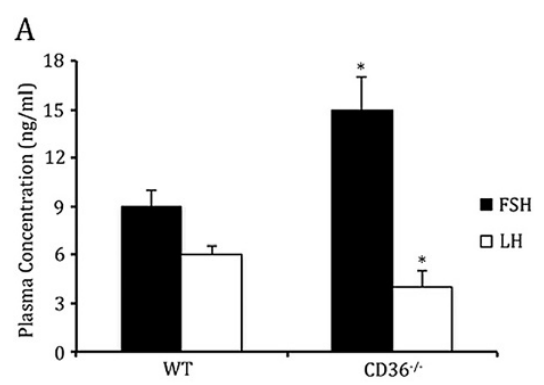

C

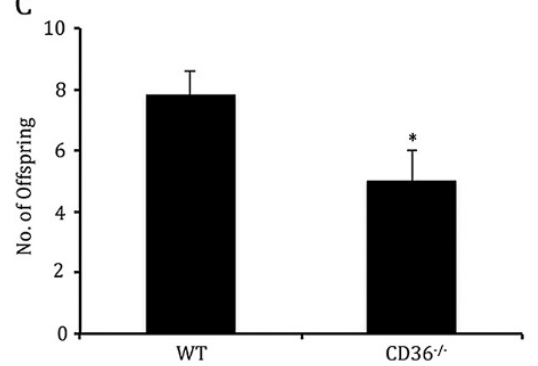

B

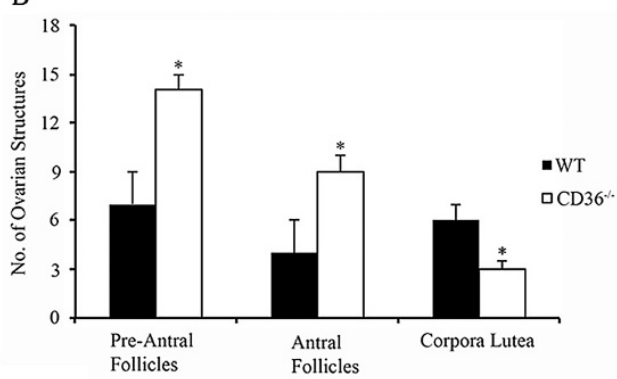

Figure 2 Serum gonadotropin levels, ovarian morphology, and number of offspring in WT and CD36-/- mice. A. ELISA was used to quantify changes FSH and LH in serum collected from $\mathrm{CD}^{-/-}$and WT mice. CD36 ${ }^{-1-}$ mice had significantly $(p<0.05)$ higher circulating FSH and lower LH levels compared to WT controls. B. Morphometric analysis was conducted on histological sections from CD36 ${ }^{-1-}$ and WT mice. Ovaries collected from $\mathrm{CD}^{-1-}$ mice had significantly $(\mathrm{p}<0.05)$ higher number of follicles and lower number of corpora lutei compared to WT controls. C. The number of offspring born to CD36-/- mice were fewer $(p<0.05)$ than WT control mice.

ovulatory phase of the cycle. Immunohistochemistry was performed to localize and quantify expression of pro-angiogenic and pro-survival VEGF and it's receptor VEGFR-2, as well as TSP-1, which is the glycoprotein that binds and activates CD36. Ovaries from $\mathrm{CD} 36^{-1-}$ mice had significantly $(\mathrm{p}<0.05)$ higher expression of VEGF and VEGFR-2 (Figure 3), while levels of TSP-1 protein remained unchanged (Figure 3 ).

\section{$\mathrm{CD}^{-1-}$ ovaries have increased proliferation and vascularity}

Ovaries from WT and CD36 ${ }^{-1-}$ mice collected at the late antral/pre-ovulatory phase of the ovarian cycle were immunostained for Ki67 to quantify cell proliferation in follicular granulosa cells. Ovaries from $\mathrm{CD}_{3} 6^{-/}$demonstrated a significant $(\mathrm{p}<0.05)$ increase in granulosa cell proliferation in both pre-antral and antral-stage follicles (Figure 4A). Cellular proliferation in corpora lutea was not statistically different between groups (Figure 4A). Immunostaining with the endothelial cell marker CD31 was also performed to quantify changes in ovarian vascularity. Ovaries from $\mathrm{CD} 36^{-1-}$ mice had a significant $(\mathrm{p}<0.01)$ increase in microvessel density compared to WT control mice (Figure 4B).

\section{Discussion}

This paper demonstrates the role of CD36 in the TSP-1 mediated effects in ovarian folliculogenesis. Based on the results of this study, CD36 appears to be an important regulator of ovarian angiogenesis, and follicular and luteal development. Disruption of expression of CD36 significantly alters ovarian morphology and expression of factors related to ovarian cell proliferation, survival, and angiogenesis. CD36 is expressed in granulosa and cumulus cells of rodents, bovines [16] and humans [27,28], although the specific function of the receptor is not completely understood.

In vitro, CD36 TSP-1 receptors are known to co-localize with VEGF receptors on cell membranes, and evidence suggests that these receptors may directly associate with each other and regulate signaling activity. We showed that knockdown of CD36 in ovarian granulosa cells resulted in an increase in expression of phosphorylated VEGFR2. The three type I repeat region of TSP-1 has been shown to reduce VEGFR2 phosphorylation and inhibit VEGF signal transduction [29] and the association between CD36, $\beta 1$ integrins, and TSP-1 is thought to be important in mediating this inhibition [30]. In the CD36 null mice, there was a significant increase in ovarian blood vessel density compared to WT controls. In these mice, there was an increase in ovarian expression of VEGF and VEGFR2 and the in vitro data in this paper suggests that removal of the inhibitory influence of CD36 would allow for enhanced phosphorylation of VEGFR2, resulting in an increase in peri-follicular and luteal angiogenesis.

Knockdown of CD36 has been shown to increase proliferation and expression of survival and angiogenic in endothelial and tumor cells [25]. In this study, CD36 


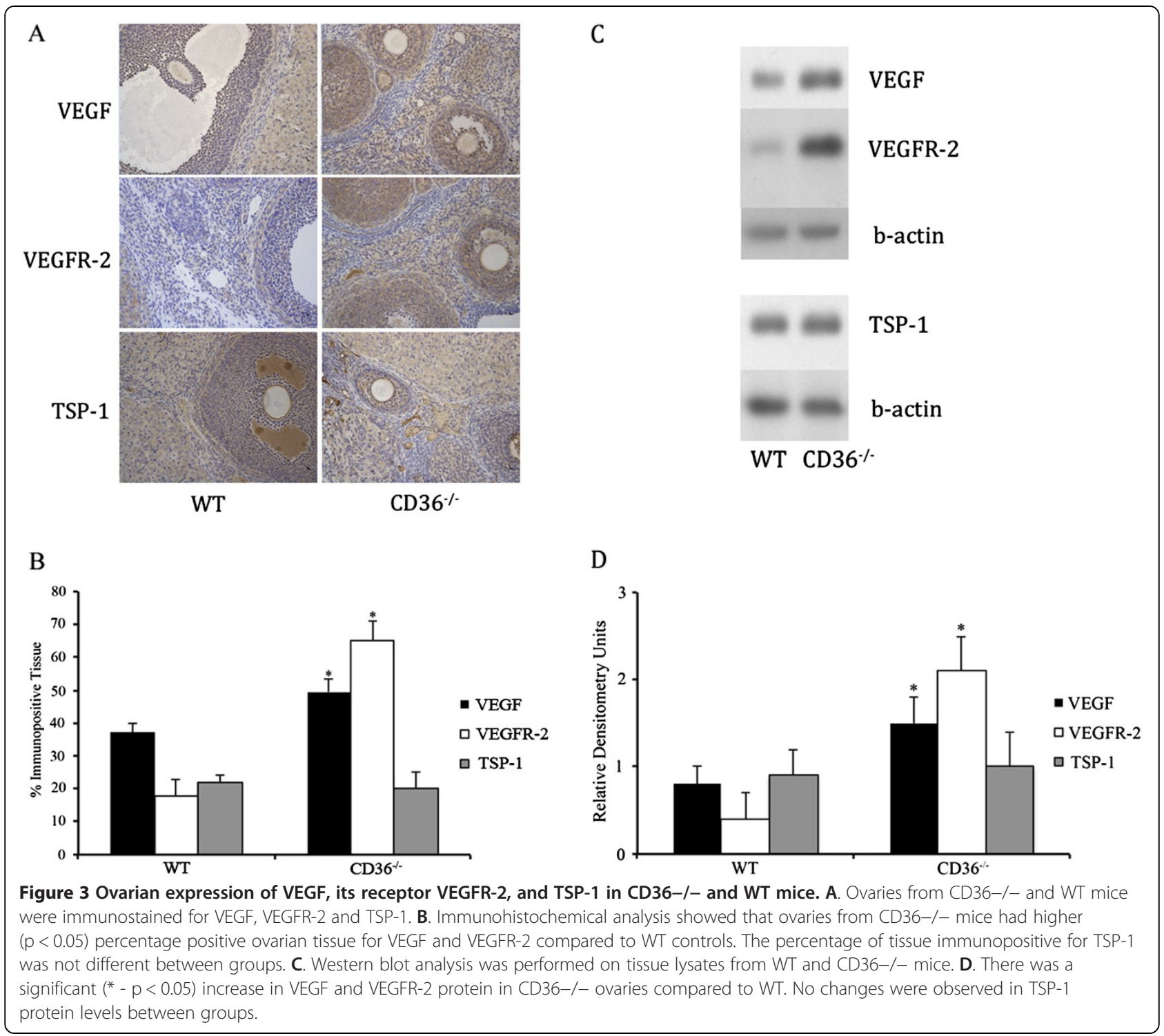

knockdown in vitro resulted in increased granulosa proliferation and survival, which was associated with increased granulosa cell expression of phosphorylated Akt. Akt phosphorylation is an important promoter of granulosa cell proliferation and viability, which are the driving forces behind follicle growth and maturation [31,32]. In vitro, the increased expression of phosphorylated Akt was associated with increased granulosa cell proliferation and decreased apoptosis. In vivo, CD36 null mice had increased granulosa cell proliferation and a greater number of growing follicles, compared to WT controls. Akt phosphorylation promotes follicle activation and survival [33] and inhibits follicle atresia $[34,35]$. Increased activity of the PI3K/Akt pathway in the absence of CD36 could also have contributed to the increased number of follicles present in the ovaries of the CD36 null mice. Thrombospondin signaling has been linked to follicle atresia previously $[15,23,24,36]$ although the mechanisms have been unclear. This paper suggests that the PI3/Akt signaling pathway may be an important mediator of TSP-1's effects in the ovary.

Normal function of the ovary is dependent on the tightly regulated angiogenic mechanisms that facilitate folliculogenesis, luteogenesis, and dissemination of the steroid hormones generated within the ovary. Angiogenesis within the ovary is a balance between and expression of pro- and anti-angiogenic factors. We have shown that members of the VEGF family and members of the anti-angiogenic TSP-1 are coordinately expressed during the ovarian cycle and have profound impacts on the angiogenic processes that occur throughout the cycle $[15,16]$. Within the ovary, cytokine action causes a downregulation of CD36, which is necessary to facilitate the explosive angiogenesis that occurs during luteal formation [37]. We showed in this study 


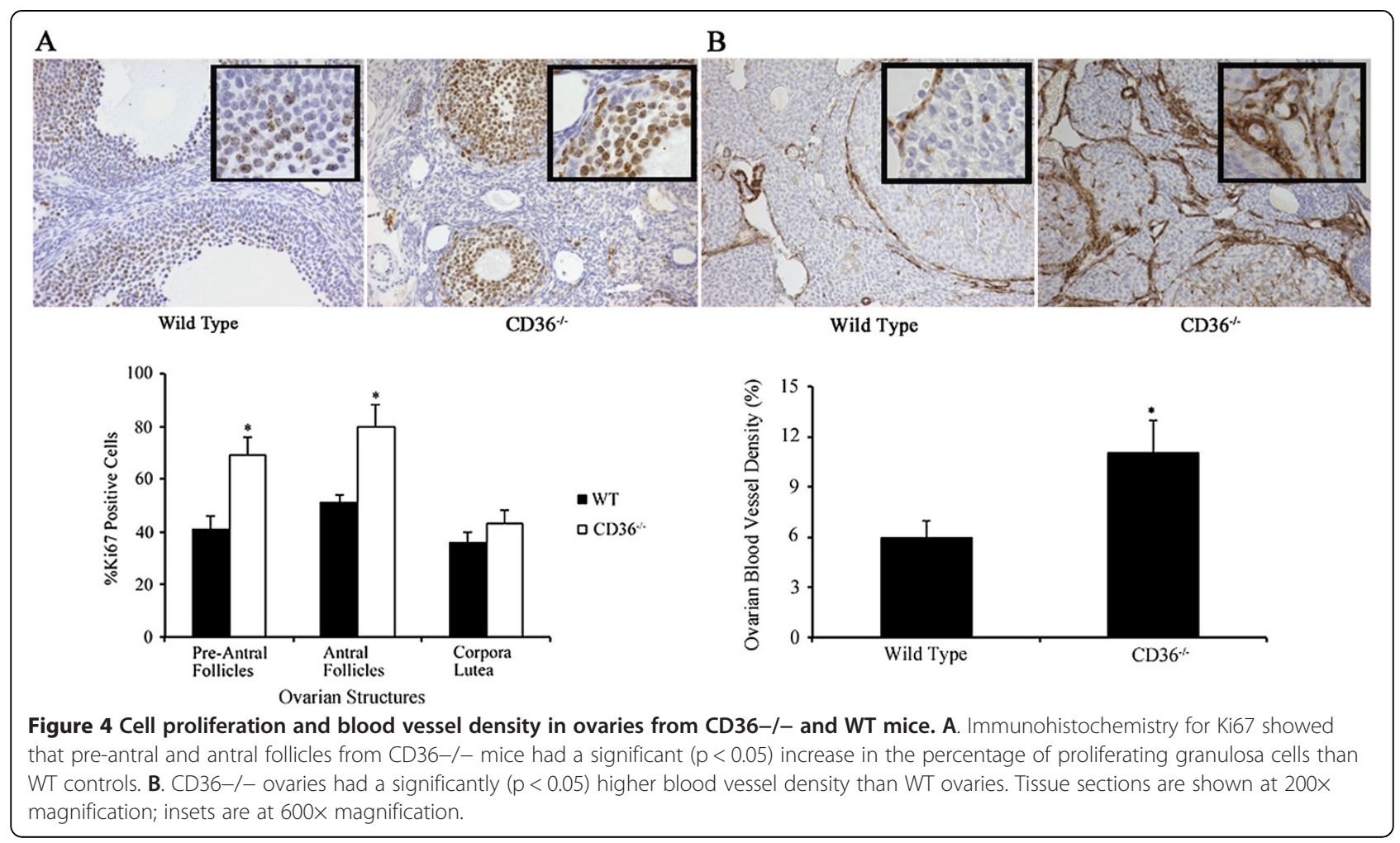

that CD36 null mice had significantly higher ovarian microvessel density compared to wildtype controls. CD36 appears to be critical in the regulation of physiological and pathophysiological angiogenesis. CD36 mediated TSP-1 signaling maintains corneal vascularity and CD36 deficiency leads to age-related corneal neovascularization while activation of CD36 can induce regression of inflammatory corneal angiogenesis [38]. CD36 has been implicated in the regulation of tumor angiogenesis. TSP-1, and other proteins containing the thrombospondin type-1 repeats (TSR), are known to endogenously inhibit the angiogenesis that occurs to facilitate tumor growth. CD36 has been shown to be required for the anti-angiogenic activity of these proteins and is absence impairs their angiogenesis inhibition and tumor vascularity increases and tumor growth is accelerated [17,39].

The morphological changes in the ovaries in the CD36 null mice somewhat replicate those seen in the condition of polycystic ovarian syndrome (PCOS) in which there is an increased number of primary follicles which remain preovulatory and do not progress to ovulation and formation of the corpus luteum [40]. In our study, CD36 null mice had an increased number of preovualtory follicles, concomitant with fewer corpora lutei, compared to WT controls. Elevated blood vessel density, and increased VEGF signaling were seen in the ovaries of the CD36 null mice and these are hallmarks of the pathogenesis of PCOS [41,42]. It has been shown that by increasing TSP-1 signaling, ovarian hypervascularization can be reversed as a method to treat PCOS [43]. Interestingly, CD36 null mice had elevated serum FSH, with suppressed LH, compared to WT controls. In classic PCOS, the hyperandrogenism and elevated GnRH generally results in an increase in the LH/FSH ratio [44]. In our mice, the elevated FSH may have been responsible for the increased number of recruited, but unovulated follicles as FSH is known to stimulate follicle development $[45,46]$ and protect against follicle atresia $[47,48]$. FSH is a potent activator of the PI3K/akt signaling pathway [49] and the elevated circulating FSH seen in the CD36 null mice may have contributed to the increased akt phosphorylation observed in the ovaries from these mice. Reduced circulating LH in the CD36 null mice may have reduced the ovulatory stimulus, resulting in the increased number of pre-ovulatory follicles and fewer corpora lutei seen in these mice. CD36 has also been implicated in the pathogenesis of PCOS due to its role in regulating metabolism. CD36 is expressed in tissues regulated to fatty acid metabolism, including adipocytes [50]. Women with PCOS often exhibit higher levels of visceral obesity [51] and elevated CD36 expression in adipose tissue is seen in women with PCOS [11], further implicating the receptor in the pathogenesis of this disease. Levels of soluble CD36 are elevated in PCOS patients, and they are associated with the altered insulin sensitivity seen in this disease [52]. The metabolic profile of the CD36 null mice was not evaluated in this study, but will be the subject of investigation in the 
future. Transcriptome analysis has been performed on follicular cells from PCOS patients and healthy women. Haouzi et al. [53] showed that cumulus cells surrounding the oocyte had differential expression of a number of growth factors and genes involved in steroid metabolism. Granulosa cell expression of genes involved in inflammation, metabolism, and coagulation has also been implicated in the pathogenesis of PCOS [54,55]. After review of the gene lists published in the various transcriptome papers, CD36 was not specifically mentioned, although the cellular process that it is involved in have been implicated. A closer evaluation and comparison of CD36 expression in samples from PCOS patients and healthy women may be warranted.

\section{Conclusions}

The results from this study suggest that TSP-1 and CD36 have important functions in the ovary and are potent regulators of follicular and luteal development, ovarian angiogenesis, and ovarian function. Disrupted expression of these proteins may be related to ovarian dysfunction and their roles in specific ovarian pathologies warrants further investigation.

\section{Competing interests}

The authors declare that they have no competing interests.

\section{Authors' contributions}

JP initiated and designed the project, performed data analysis and wrote the manuscript. KO performed the in vitro CD36 knockdown experiments and MR performed the immunohistochemistry and Western blot analysis. All authors read and approved the final manuscript version.

\section{Acknowledgements}

This work was supported by the Natural Sciences and Engineering Research Council of Canada (Grant Number 400069) and the Canadian Institutes of Health Research (Grant Number 450084).

Received: 30 August 2013 Accepted: 22 February 2014

Published: 14 March 2014

\section{References}

1. Greenaway J, Connor K, Pedersen HG, Coomber BL, LaMarre J, Petrik J: Vascular endothelial growth factor and its receptor, Flk-1/KDR, are cytoprotective in the extravascular compartment of the ovarian follicle. Endocrinology 2004, 145:2896-2905.

2. Lawler J: The functions of thrombospondin-1 and-2. Curr Opin Cell Biol 2000, 12:634-640.

3. Lawler J: Thrombospondin-1 as an endogenous inhibitor of angiogenesis and tumor growth. J Cell Mol Med 2002, 6:1-12.

4. Adams JC, Lawler J: The thrombospondins. Int J Biochem Cell B 2004, 36:961-968.

5. Adams JC, Lawler J: The thrombospondins. Cold Spring Harbor perspectives in biology 2011, 3:a009712.

6. Silverstein RL: The face of TSR revealed: an extracellular signaling domain is exposed. J Cell Biol 2002, 159:203-206.

7. Lawler J, Detmar M: Tumor progression: the effects of thrombospondin-1 and -2. Int J Biochem Cell B 2004, 36:1038-1045.

8. Ren B, Yee KO, Lawler J, Khosravi-Far R: Regulation of tumor angiogenesis by thrombospondin-1. Biochim Biophys Acta 2006, 1765:178-188

9. Kulapaditharom B, Boonkitticharoen V, Sritara C: Plasma vascular endothelial growth factor dysregulation in defining aggressiveness of head and neck squamous cell carcinoma. J Oncol 2012, 2012:687934.
10. Koukourakis MI, Limberis V, Tentes I, Kontomanolis E, Kortsaris A, Sivridis E, Giatromanolaki A: Serum VEGF levels and tissue activation of VEGFR2/ KDR receptors in patients with breast and gynecologic cancer. Cytokine 2011, 53:370-375.

11. Seow KM, Tsai YL, Hwang JL, Hsu WY, Ho LT, Juan CC: Omental adipose tissue overexpression of fatty acid transporter CD36 and decreased expression of hormone-sensitive lipase in insulin-resistant women with polycystic ovary syndrome. Hum Reprod 1982-1988, 2009:24

12. Zhou J, Febbraio M, Wada T, Zhai Y, Kuruba R, He J, Lee JH, Khadem S, Ren $\mathrm{S}$, Li S, Silverstein RL, Xie W: Hepatic fatty acid transporter Cd36 is a common target of LXR, PXR, and PPARgamma in promoting steatosis. Gastroenterology 2008, 134:556-567.

13. Silverstein RL, Febbraio M: CD36, a scavenger receptor involved in immunity, metabolism, angiogenesis, and behavior. Sci Signal 2009, 2:re3.

14. Febbraio M, Hajjar DP, Silverstein RL: CD36: a class B scavenger receptor involved in angiogenesis, atherosclerosis, inflammation, and lipid metabolism. J Clin Invest 2001, 108:785-791.

15. Greenaway J, Gentry PA, Feige JJ, LaMarre J, Petrik JJ: Thrombospondin and vascular endothelial growth factor are cyclically expressed in an inverse pattern during bovine ovarian follicle development. Biol Reprod 2005, 72:1071-1078

16. Petrik JJ, Gentry PA, Feige JJ, LaMarre J: Expression and localization of thrombospondin- 1 and -2 and their cell-surface receptor, $C D 36$, during rat follicular development and formation of the corpus luteum. Biol Reprod 2002, 67:1522-1531.

17. Hale JS, Li M, Sinyuk M, Jahnen-Dechent W, Lathia JD, Silverstein RL: Context dependent role of the CD36-thrombospondin-histidine-rich glycoprotein axis in tumor angiogenesis and growth. PloS One 2012, 7:e40033.

18. Silverstein RL, Febbraio M: CD36-TSP-HRGP interactions in the regulation of angiogenesis. Curr Pharm Design 2007, 13:3559-3567.

19. Rege TA, Stewart J Jr, Dranka B, Benveniste EN, Silverstein RL, Gladson CL: Thrombospondin-1-induced apoptosis of brain microvascular endothelial cells can be mediated by TNF-R1. J Cell Physiol 2009, 218:94-103.

20. Isenberg JS, Martin-Manso G, Maxhimer JB, Roberts DD: Regulation of nitric oxide signalling by thrombospondin 1: implications for anti-angiogenic therapies. Nat Rev Canc 2009, 9:182-194.

21. Jimenez B, Volpert OV, Crawford SE, Febbraio M, Silverstein RL, Bouck N: Signals leading to apoptosis-dependent inhibition of neovascularization by thrombospondin-1. Nat Med 2000, 6:41-48.

22. Greenaway J, Lawler J, Moorehead R, Bornstein P, Lamarre J, Petrik J: Thrombospondin-1 inhibits VEGF levels in the ovary directly by binding and internalization via the low density lipoprotein receptor-related protein-1 (LRP-1). J Cell Physiol 2007, 210:807-818.

23. Garside SA, Harlow CR, Hillier SG, Fraser HM, Thomas FH: Thrombospondin-1 inhibits angiogenesis and promotes follicular atresia in a novel in vitro angiogenesis assay. Endocrinology 2010, 151:1280-1289.

24. Garside SA, Henkin J, Morris KD, Norvell SM, Thomas FH, Fraser HM: A thrombospondin-mimetic peptide, ABT-898, suppresses angiogenesis and promotes follicular atresia in pre- and early-antral follicles in vivo. Endocrinology 2010, 151:5905-5915.

25. Greenaway J, Henkin J, Lawler J, Moorehead R, Petrik J: ABT-510 induces tumor cell apoptosis and inhibits ovarian tumor growth in an orthotopic, syngeneic model of epithelial ovarian cancer. Mol Cancer Ther 2009, 8:64-74.

26. Stein LS, Stoica G, Tilley R, Burghardt RC: Rat ovarian granulosa cell culture: a model system for the study of cell-cell communication during multistep transformation. Cancer Res 1991, 51:696-706.

27. Robker RL, Akison LK, Bennett BD, Thrupp PN, Chura LR, Russell DL, Lane M, Norman RJ: Obese women exhibit differences in ovarian metabolites, hormones, and gene expression compared with moderate-weight women. J Clin Endocr Metab 2009, 94:1533-1540.

28. Serke H, Bausenwein J, Hirrlinger J, Nowicki M, Vilser C, Jogschies P, Hmeidan FA, Blumenauer V, Spanel-Borowski K: Granulosa cell subtypes vary in response to oxidized low-density lipoprotein as regards specific lipoprotein receptors and antioxidant enzyme activity. J Clin Endocr Metab 2010, 95:3480-3490.

29. Zhang X, Kazerounian S, Duquette M, Perruzzi C, Nagy JA, Dvorak HF, Parangi S, Lawler J: Thrombospondin-1 modulates vascular endothelial growth factor activity at the receptor level. FASEB J 2009, 23:3368-3376.

30. Primo L, Ferrandi C, Roca C, Marchio S, di Blasio L, Alessio M, Bussolino F: Identification of CD36 molecular features required for its in vitro angiostatic activity. FASEB J 2005, 19:1713-1715. 
31. Goto M, Iwase A, Ando H, Kurotsuchi S, Harata T, Kikkawa F: PTEN and Akt expression during growth of human ovarian follicles. J Assist Reprod Gen 2007, 24:541-546.

32. Zhang P, Chao H, Sun X, Li L, Shi Q, Shen W: Murine folliculogenesis in vitro is stage-specifically regulated by insulin via the Akt signaling pathway. Histochem Cell Biol 2010, 134:75-82.

33. Sobinoff AP, Nixon B, Roman SD, McLaughlin EA: Staying alive: PI3K pathway promotes primordial follicle activation and survival in response to 3MC-induced ovotoxicity. Toxicol Sci 2012, 128:258-271.

34. Craig J, Orisaka M, Wang H, Orisaka S, Thompson W, Zhu C, Kotsuji F, Tsang BK: Gonadotropin and intra-ovarian signals regulating follicle development and atresia: the delicate balance between life and death. Frontiers Biosci 2007, 12:3628-3639.

35. Parborell F, Abramovich D, Irusta G, Tesone M: Angiopoietin 1 reduces rat follicular atresia mediated by apoptosis through the PI3K/Akt pathway. Mol Cell Endocrinol 2011, 343:79-87.

36. Thomas FH, Wilson $\mathrm{H}$, Silvestri A, Fraser HM: Thrombospondin-1 expression is increased during follicular atresia in the primate ovary. Endocrinology 2008, 149:185-192.

37. Galvao A, Henriques S, Pestka D, Lukasik K, Skarzynski D, Mateus LM, Ferreira-Dias GM: Equine luteal function regulation may depend on the interaction between cytokines and vascular endothelial growth factor: an in vitro study. Biol Reprod 2012, 86:187.

38. Mwaikambo BR, Yang C, Ong H, Chemtob S, Hardy P: Emerging roles for the CD36 scavenger receptor as a potential therapeutic target for corneal neovascularization. Endoc Metab Immune Disord Drug Targets 2008, 8:255-272.

39. Kaur B, Cork SM, Sandberg EM, Devi NS, Zhang Z, Klenotic PA, Febbraio M, Shim H, Mao H, Tucker-Burden C, Silverstein RL, Brat DJ, Olson JJ, Van Meir EG: Vasculostatin inhibits intracranial glioma growth and negatively regulates in vivo angiogenesis through a CD36-dependent mechanism. Cancer Res 2009, 69:1212-1220.

40. Maciel GA, Baracat EC, Benda JA, Markham SM, Hensinger K, Chang RJ, Erickson GF: Stockpiling of transitional and classic primary follicles in ovaries of women with polycystic ovary syndrome. J Clin Endocr Metab 2004, 89:5321-5327.

41. Abramovich D, Irusta G, Bas D, Cataldi NI, Parborell F, Tesone M: Angiopoietins/TIE2 system and VEGF are involved in ovarian function in a DHEA rat model of polycystic ovary syndrome. Endocrinology 2012, 153:3446-3456.

42. Artini PG, Monti M, Matteucci C, Valentino V, Cristello F, Genazzani AR: Vascular endothelial growth factor and basic fibroblast growth factor in polycystic ovary syndrome during controlled ovarian hyperstimulation. Gynecol Endocrinol 2006, 22:465-470.

43. Tan BK, Adya R, Chen J, Farhatullah S, Heutling D, Mitchell D, Lehnert H, Randeva HS: Metformin decreases angiogenesis via NF-kappaB and Erk1/ 2/Erk5 pathways by increasing the antiangiogenic thrombospondin-1. Cardiovasc Res 2009, 83:566-574.

44. Fulghesu AM, Cucinelli F, Pavone V, Murgia F, Guido M, Caruso A, Mancuso $S$, Lanzone $A$ : Changes in luteinizing hormone and insulin secretion in polycystic ovarian syndrome. Hum Reprod 1999, 14:611-617.

45. Halpin DM, Charlton HM: Effects of short-term injection of gonadotrophins on ovarian follicle development in hypogonadal (hpg) mice. J Reprod Fertil 1988, 82:393-400.

46. McNeilly JR, Watson EA, White YA, Murray AA, Spears N, McNeilly AS: Decreased oocyte DAZL expression in mice results in increased litter size by modulating follicle-stimulating hormone-induced follicular growth. Biol Reprod 2011, 85:584-593.

47. Lin P, Rui R: Effects of follicular size and FSH on granulosa cell apoptosis and atresia in porcine antral follicles. Mol Reprod Dev 2010, 77:670-678.

48. Wang XL, Wu Y, Tan LB, Tian Z, Liu JH, Zhu DS, Zeng SM: Folliclestimulating hormone regulates pro-apoptotic protein $\mathrm{BCl}$-2-interacting mediator of cell death-extra long (BimEL)-induced porcine granulosa cell apoptosis. J Biol Chem 2012, 287:10166-10177.

49. Hunzicker-Dunn ME, Lopez-Biladeau B, Law NC, Fiedler SE, Carr DW, Maizels ET: PKA and GAB2 play central roles in the FSH signaling pathway to PI3K and AKT in ovarian granulosa cells. Proc Natl Acad Sci U S A 2012, 109:E2979--2988.

50. Zhou D, Samovski D, Okunade AL, Stahl PD, Abumrad NA, Su X: CD36 level and trafficking are determinants of lipolysis in adipocytes. FASEB J 2012, 26:4733-4742.
51. Aroda V, Ciaraldi TP, Chang SA, Dahan MH, Chang RJ, Henry RR: Circulating and cellular adiponectin in polycystic ovary syndrome: relationship to glucose tolerance and insulin action. Fertil Steril 2008, 89:1200-1208.

52. Glintborg D, Hojlund $\mathrm{K}$, Andersen M, Henriksen JE, Beck-Nielsen $\mathrm{H}_{\text {, }}$ Handberg A: Soluble CD36 and risk markers of insulin resistance and atherosclerosis are elevated in polycystic ovary syndrome and significantly reduced during pioglitazone treatment. Diabetes Care 2008, 31:328-334.

53. Haouzi D, Assou S, Monzo C, Vincens C, Dechaud H, Hamamah S: Altered gene expression profile in cumulus cells of mature MII oocytes from patients with polycystic ovary syndrome. Hum Reprod 2012, 27:3523-3530.

54. Kaur S, Archer KJ, Devi MG, Kriplani A, Strauss JF 3rd, Singh R: Differential gene expression in granulosa cells from polycystic ovary syndrome patients with and without insulin resistance: identification of susceptibility gene sets through network analysis. J Clin Endocr Metab 2012, 97:E2016-E2021.

55. Schmidt J, Weijdegard B, Mikkelsen AL, Lindenberg S, Nilsson L, Brannstrom $M$ : Differential expression of inflammation-related genes in the ovarian stroma and granulosa cells of PCOS women. Mol Hum Reprod 2013, 20:49-58.

doi:10.1186/1477-7827-12-21

Cite this article as: Osz et al:: The thrombospondin-1 receptor CD36 is an important mediator of ovarian angiogenesis and folliculogenesis. Reproductive Biology and Endocrinology 2014 12:21.

\section{Submit your next manuscript to BioMed Central and take full advantage of:}

- Convenient online submission

- Thorough peer review

- No space constraints or color figure charges

- Immediate publication on acceptance

- Inclusion in PubMed, CAS, Scopus and Google Scholar

- Research which is freely available for redistribution 